\title{
Ancestry estimation based on morphoscopic traits in a sample of African slaves from Lagos, Portugal (15th-17th centuries)
}

\begin{tabular}{|r|l|}
\hline Journal: & International Journal of Osteoarchaeology \\
\hline Manuscript ID & OA-16-0026.R1 \\
\hline Wiley - Manuscript type: & Short Report \\
\hline Date Submitted by the Author: & n/a \\
\hline Complete List of Authors: & $\begin{array}{l}\text { Coelho, Catarina; University of Coimbra, Department of Life Sciences } \\
\text { Navega, David; University of Coimbra, Department of Life Sciences } \\
\text { Eugenia, Cunha; Universidade de Coïmbra, Departamento de Antropologia } \\
\text { Ferreira, Maria Teresa; University of Coimbra, Department of Life } \\
\text { Sciences; } \\
\text { Wasterlain, Sofia; University of Coimbra, Department of Life Sciences }\end{array}$ \\
\hline Keywords: & $\begin{array}{l}\text { Ancestry, Morphoscopic traits, Enslaved Africans, 15th-17th centuries, } \\
\text { Bioarchaeology }\end{array}$ \\
\hline &
\end{tabular}

SCHOLARONE ${ }^{m}$

Manuscripts 


\section{Ancestry estimation based on morphoscopic traits in a sample of African slaves from Lagos, Portugal $\left(15^{\text {th }}-17^{\text {th }}\right.$ centuries $)$}

\section{Catarina Coelho $^{\text {a,b* }}$, David Navega ${ }^{\text {a,b }}$, Eugénia Cunha ${ }^{a, b}$, Maria Teresa Ferreira ${ }^{\text {a,b,c }}$, Sofia N. Wasterlain $^{\text {b,c }}$}

${ }^{\text {a }}$ Laboratory of Forensic Anthropology, Department of Life Sciences, University of Coimbra, Coimbra, Portugal

${ }^{\mathrm{b}}$ Centre for Functional Ecology, University of Coimbra, Coimbra, Portugal

${ }^{\mathrm{c}}$ Research Centre for Anthropology and Health, Department of Life Sciences, University of Coimbra, Coimbra, Portugal

Running Title: Ancestry estimation in a slave sample from Portugal

Key words: Ancestry; Morphoscopic traits; Enslaved Africans; $15^{\text {th }}-17^{\text {th }}$ centuries; Bioarchaeology.

*Corresponding author:

Catarina Coelho

Department of Life Sciences, University of Coimbra, Calçada Martim de Freitas, 3000-456

Coimbra, Portugal

Telephone: +351916519858

Fax: +351239854129

E-mail address: coelho.catarina.rs@gmail.com 


\section{Abstract}

In 2009, a skeletal collection of 158 individuals was excavated in Valle da Gafaria, Lagos, Portugal. These individuals were buried in an unusual way, having been discarded in an urban dump located outside the medieval city walls, dated from the $15^{\text {th }}-17^{\text {th }}$ centuries. Lagos was, at the time, an important slave trade harbour, and during the excavation, the morphological appearance of the skulls and the presence of intentionally modified teeth in some individuals raised suspicion that they were African slaves. Despite the extensive historical information about the Atlantic slave trade, so far skeletal remains identified as slaves were scarce, especially in Europe. The aim of the present study is to estimate the ancestry of a sample of 33 adult individuals ( 28 females and 5 males) recovered in the Valle da Gafaria applying the eleven morphological characteristics recommended by Hefner (2009) using the naïve Bayes classifier. When comparing the individuals with four groups of classification (European, African, American Indian, and Asian), 24 (72.7\%) specimens were classified as Africans with a posterior probability greater than 0.90 . When only two groups were considered (the African and the European), 31 (93.9\%) individuals were classified as Africans with a posterior probability greater than 0.90 . These results are in accordance with the historical record and previous genetic studies suggesting that this sample represents a rare archaeological sample of great interest to the history of the Atlantic slave trade, i.e., the Lagos individuals were probably of African ancestry. Although the ancestry is a parameter of the biological profile mainly estimated in forensic Anthropology, this study confirms the importance of its investigation in past populations.

Key words: Ancestry; Morphoscopic traits; Enslaved Africans; $15^{\text {th }}-17^{\text {th }}$ centuries; Bioarchaeology. 


\section{Introduction}

Due to the construction of an underground car park in Valle da Gafaria (Lagos, Portugal), an archaeological excavation allowed the identification of two burial places: one related with a leprosarium (Ferreira et al., 2013) and another associated with a deposit of urban waste (Wasterlain et al., 2015). From this deposit of urban waste, dated from the $15^{\text {th }}-17^{\text {th }}$ centuries, the skeletons of 158 individuals were recovered.

The radiocarbon dating of one skeleton (individual 169) revealed a date of 450 +/- 40BP (2 sigma: Cal AD 1420 - 1480; cal BP 540 - 470; Beta - 276508). During that period, the $15^{\text {th }}$ century, Lagos was the harbour where slaves arrived from Africa and from which they were redistributed to the Kingdom of Portugal, the Mediterranean Sea and Northern Europe (Fonseca, 2010; Caldeira, 2013). Additionally, several archaeological findings support the hypothesis that the 158 individuals recovered from the deposit waste were African slaves: the fact that their bodies were dropped mixed with waste in a large pit, disregarding the burial traditions; the recovery of several African ornaments associated with the skeletons; the apparent African facial morphology (Figure 1) (Coelho, 2012); and the presence of intentionally modified teeth in 63 individuals. For a more comprehensive contextualization of this collection please see Wasterlain et al. (2015).

The aim of the present study is to estimate the ancestry of a sample of individuals recovered in the Valle da Gafaria by applying the eleven morphological characteristics recommended by Hefner (2009) using the naïve Bayes classifier.

The ability to identify potential slaves will lead to several pertinent questions about the slave trade, such as: Were both sexes equally likely to be victims in the slave trade? What was the health status of these individuals? Is there any evidence of patterned degenerative lesions that indicate that the slaves were used for heavy manual labour? Is there any evidence of traumatic injuries that may suggest that these individuals were subjected to physical abuse? After confirming that these 
individuals were African slaves future research on this collection could help address this kind of questions of wider anthropological interest.

\section{Material and Methods}

The morphological analysis is based on two different types of nonmetric traits, the anthroposcopic traits, and the binary nonmetric traits (Hughes et al., 2011). While the anthroposcopic traits evaluate the different degrees of expression or shape of the trait (e.g. the malar tubercle), the binary nonmetric traits are recorded as "present" or "absent" (e.g. the nasal overgrowth) (Hughes et al., 2011). In the present study, the anthroposcopic traits recommended by Hefner (2009) were applied using the naïve Bayes classifier to estimate ancestry of the individuals recovered in Valle da Gafaria (Lagos, Portugal).

Of the 158 individuals of the Valle da Gafaria collection, only 33 were sufficiently preserved to allow morphological analysis. The state of preservation and completeness of the selected skeletons are presented in Table 1. Sex and age-at-death estimation, relied on metric and morphological analyses of the coxal bone and the skull (Uytterschaut, 1986; Ferembach et al., 1990; Buikstra and Ubelaker, 1994; Bruzek, 2002; Ozle et al., 2007; Shirley and Jantz, 2011). The ages are comprised between 15 and 40 years. In all, the sample is composed of 28 females and 5 males (Table 1). In the present study the sexes were combined together because the reference data provided by Hefner (2009) also pool the sexes. Besides, there are no issues with the unequal samples in the current study.

Eleven morphological characteristics were observed to estimate ancestry: anterior nasal spine (ANS), inferior nasal aperture (INA), interorbital breadth (IOB), malar tubercle (MT), nasal aperture width (NAW), nasal bone contour (NBC), nasal overgrowth (NO), postbregmatic depression (PBD), supranasal suture (SPS), transverse palatine suture (TPS Shape), 
zygomaticomaxillary suture (ZS Shape). All characteristics were evaluated following the descriptions of Hefner (2009) and the images of Osteoware (Smithsonian Institution, 2011).

The first step of this investigation was to ascertain if there was agreement between two observations performed by the same observer (intra-observer error) and by two different observers (inter-observer error). To assess intra-observer error, observations were collected with one week interval between each observation by the first author (CC). To investigate the inter-observer error 17 skulls were analysed by another author (MTF). Both errors were calculated through the Cohen's Kappa coefficient, measured on a -1 to 1 scale (Viera and Garrett, 2005).

Ancestry estimation can be formulated and addressed from a mathematical point of view as a statistical classification problem, that is, to allocate an object into predefined classes based on its observed features. Statistical classification and pattern recognition tools are common in anthropology because biological profiling from skeletal remains is in its essence an exercise of statistical prediction and estimation. To be able to estimate sex, age-at-death, ancestry, and stature, statistical information must be first extracted from identified reference samples. Such information can be later used to reconstruct any biological parameter from unidentified skeletal remains based on the characteristics of the osteological material. The accuracy and precision of such reconstruction depends on the quality of the methods of osteological observation and the techniques underlying statistical prediction and estimation.

Hefner and Ousley (2014) provided a significant contribution to statistical ancestry estimation by morphoscopic analysis. The authors evaluated the utility of several statistical algorithms in ancestry prediction, demonstrating that morphoscopic ancestry estimation can also be framed within a robust mathematical approach. Their work, however, is incomplete in the sense that the statistical models created and tested by the authors lack a practical and easy-to-use implementation. In fact, some of the techniques employed are impossible to use without specialized software (i.e., neural network, random forest, and support vector machine models). 
Among the techniques used is the naïve Bayes algorithm. The naïve Bayes classifier is a simple, yet effective, probabilistic model that makes use of Bayesian theory with strong independence assumption (Fielding, 2007). It assumes that the presence or absence of a characteristic is not related to the presence or absence of another trait given the class variable, that is, it takes no account for partial correlations. Such assumption is called conditional independence. This modelling assumption offers a dramatic simplification of model induction: individual classconditional marginal density of features can be estimated separately using a one-dimensional kernel density estimator or any distribution model appropriate for the continuous data. For discrete predictor class-conditional probability tables can be obtained using a histogram estimator (Hastie et al., 2009).

It is important to note that unless the data is projected into a subspace with forced orthogonality (i.e., PCA scores), it is common to observe some degree of dependency among predictors, which normally occurs in real data. However, even when there are deviations from this underlying independence assumption, this technique works well often outperforming more sophisticated algorithms that explicitly model dependencies. This occurs because model predictions will be accurate as long as probability for the true class (i.e., ancestry) is greater than the probability of any other class. To obtain correct predictions only an approximate solution is required to rank order class probabilities. Marginal class-conditional densities may be biased but that has little effect on the final posterior probabilities, especially in the decision regions (Fielding, 2007; Hastie et al., 2009).

Under the naïve Bayes classifier ancestry estimation is expressed as:

$$
P\left(A_{k} \mid X_{i}\right)=\frac{P\left(A_{K}\right) \prod_{i=1}^{p} P\left(X_{i} \mid A_{k}\right)}{P\left(X_{i}\right)}=\frac{P\left(A_{K}\right) \prod_{i=1}^{p} P\left(X_{i} \mid A_{k}\right)}{\sum_{i=1}^{r} P\left(A_{K}\right) \prod_{i=1}^{p} P\left(X_{i} \mid A_{k}\right)}
$$


Where A stands for ancestral group, $\mathrm{X}$ for the morphoscopic traits, $\mathrm{r}$ is the number of ancestral groups involved in the analysis, and $\mathrm{p}$ the number of morphoscopic traits used to compute the posterior probability.

To assess ancestry using this statistical approach, the posterior probability that a skull is from a specific ancestry, given $\mathrm{p}$ observed traits, is computed for each ancestral group considered in the analysis. The ancestral group that maximizes the posterior probability is considered as the most likely. In this study, the prior probability for each ancestral group, $\mathrm{P}\left(\mathrm{A}_{\mathrm{k}}\right)$, was assumed to be uniform.

The main advantage of the naïve Bayes classifier is that it only requires knowledge of probabilities to obtain ancestry estimates. In this case the most important one is $P\left(X_{i} \mid A_{k}\right)$, the probability of observing a specific stage/state of a morphological trait given that ancestry is known. Bayes' theorem is then used to invert these probabilities and obtain $P\left(A_{k} \mid X_{i}\right)$, i.e. the probability of a skull being of a certain ancestry given the observed morphological trait(s). The required probabilities $P\left(X_{i} \mid A_{k}\right)$ are available from Hefner (2009), and allowed us to construct a naïve Bayes classifier. Also, detailed information regarding the reference samples, namely their size, composition, chronology, and geographic origin, can be obtained from Hefner (2009). A web application that implements the naïve Bayes classifier for morphoscopic ancestry estimation is available at www.apps.osteomics.com/hefneR.

Two predictive analyses were conducted based on the number of biogeographic ancestral groups. The first analysis included four ancestral groups (European, African, American Indian, and Asian). The second analysis was restricted to European and African ancestral groups. As previously mentioned, statistical classification was performed based on the maximization of posterior probability principle, the ancestral group with the highest posterior probability was assigned to the 
individual. It means that under a uniform prior, the assigned ancestral group is the one with a posterior probability greater than the (prior) random allocation probability.

\section{Results}

Intra- and inter-observer errors

The results of the Cohen's Kappa coefficient for the intra- and inter-observer errors are presented in Table 2. Following the interpretation of Kappa by Viera and Garrett (2005), the overall results showed substantial agreement. More specifically, in the intra-observer analysis, the zygomaticomaxillary suture $(K=0.459)$ showed a moderate agreement. The inferior nasal aperture $(K=0.629)$, the malar tubercle $(K=0.718)$ the supranasal suture $(K=0.770)$, and the anterior nasal spine $(K=0.798)$ demonstrated a substantial agreement. The other five traits - nasal bone contour $(K=0.812)$, transverse palatine suture $(K=0.816)$, nasal aperture width $(K=0.829)$, postbregmatic depression $(K=0.927)$, interorbital breadth $(K=0.933)$ - showed an almost perfect agreement. The nasal overgrowth $(K=1)$ presented a perfect agreement between the two observations.

Regarding the inter-observer error, the malar tubercle $(K=0.186)$ showed a slight agreement. The zygomaticomaxillary suture $(K=0.214)$ and the supranasal suture $(K=0.393)$ showed a fair agreement. Four traits - anterior nasal spine $(K=0.500)$, inferior nasal aperture $(K=0.553)$, nasal bone contour $(K=0.553)$, and the interorbital breadth $(K=0.589)$ - presented moderate agreement. The transverse palatine suture $(K=0.827)$ had an almost perfect agreement. The nasal aperture width $(K=1)$, the nasal overgrowth $(K=1)$, and the postbregmatic depression $(K=1)$ showed a perfect agreement among the two observers.

\section{Four groups classification}

The results obtained by using the naïve Bayes classifier on the first analysis are presented in Table 3. Twenty-four specimens (72.7\%) were classified as Africans with posterior probability 
greater than 0.90 . Two individuals (6.1\%) were assigned to the African group with posterior probability greater than 0.80 . Three specimens (9.1\%) were classified as Africans with posterior probability greater than 0.70 . Two skulls $(6.1 \%)$ were classified in the African group with posterior probability greater than 0.50 . One individual (3.0\%) was classified as African with a 0.44 posterior probability. Finally, one cranium (3.0\%), from the individual 63 , had posterior probability greater than 0.60 to belong to the American Indian group (Figure 2).

\section{Two groups classifications}

The results of the second analysis using only two groups, European and African, are presented in Table 4. Thirty-one individuals (93.9\%) were classified as Africans with posterior probability greater than 0.90 . Only two specimens (6.1\%) were classified as Africans with posterior probability greater than 0.80 .

\section{Discussion}

Generally, the estimation of ancestry is considered more relevant for Forensic Anthropology than for past population studies, since it is one of the big four generic factors of a biological profile that help to establish identity and strong contextual information is usually associated with bioarchaeological investigations (i.e., artefacts, chronology, location) making ancestry estimation and the bio-geographic origin of a particular population implicit. However, there are several situations where it is worth investigating ancestry in archaeological samples, namely when the history of colonization of a given region is being investigated, in studies of endogamy vs. exogamy, when different facial morphologies inside a close group suggests the presence of newcomer individuals, and to confirm the identity when investigating historical characters. Finally, ancestry is a crucial factor in the study of the history of slavery. 
As a parameter of paramount importance, the estimation of ancestry has attracted the attention of researchers in order to find more accurate methods of evaluation (Gill, 2009, Hefner, 2009; DiGangi and Hefner, 2013). The estimation of ancestry is preferably accomplished through analysis of the skull, particularly from the delicate bones of the mid-face, because this region is the most discriminant part of the skeleton (Gill, 2009). However, the most discriminative features are commonly reported only for three major population groups - the European, the African, and the Asian (Byers, 2011) - which makes it difficult to identify small-scale migrations in the past.

Morphological analysis to estimate ancestry has been largely criticized for being highly subjective and dependent on the experience of the observer. However, it has some advantages over metric analysis. For instance, the morphological traits are easily observed, not being required instruments (Hefner and Ousley, 2014). Moreover, along with adequate statistical approaches, the morphoscopic traits can be used to accurately assess the ancestry, without relying only on the experience of the observer (Iscan and Steyn, 2013; Hefner and Ousley, 2014).

The skeletal collection recovered in the Valle da Gafaria (Lagos, Portugal) is a unique sample composed of the remains of 158 individuals who lived in the $15^{\text {th }}-17^{\text {th }}$ centuries, and who were dropped in a dump after death, disregarding the canonical burial traditions. The Lagos's historical context and the presence of many individuals with intentionally modified teeth (for more details, please see Wasterlain et al., 2015) are among the facts that led the authors to suspect that these skeletons were the remains of African slaves who arrived to the Lagos's harbour during that time period. Therefore, this study aimed to estimate the ancestry of 33 adult individuals ( 28 females and 5 males), applying the eleven morphological characteristics recommended by Hefner (2009) using the naïve Bayes classifier.

Overall, the results obtained in the present study confirmed the African ancestry of the Lagos's individuals. More specifically, the comparison of the 33 skulls with the four major ancestral groups (European, African, American Indian, and Asian) assigned 24 (72.7\%) to an 
African ancestry with a posterior probability greater than 0.90 . Surprisingly, one individual (number 63) was assigned to the American Indian group. As it can be observed in Figure 2, the cranium 63 presents some traits that are shared by Africans and American Indians, such as the inferior nasal aperture, and the interorbital breadth. It should not be ignored, however, that this skull was incomplete, fragmented, and it was necessary to proceed to its reconstruction, which certainly contributed and increased its post-mortem deformation. In fact, the nasal overgrowth and the postbregamatic depression are two characteristics that are important to distinguish these two ancestries and that were not possible to observe in this individual. These circumstances may have biased the obtained result. On the other hand, the likelihood of encountering an America Indian within this sample is quite low.

The results obtained when only two groups were considered (the African and the European) were even more consistent with an African origin, since 31 (93.9\%) individuals were classified as Africans with a posterior probability greater than 0.90 .

In 2014, Martiniano et al. obtained random short autosomal sequence reads from two individuals (125 and 166) recovered in the discard deposit burials from Valle da Gafaria, from which only one was also included in the present analysis. Interestingly, the next generation sequencing (NGS) of historical DNA sampled from the metatarsal bone of the individual 125 showed affinity with Bantu-speaking groups and Western African Mandenka and Yoruba populations, which is also consistent with African origins for these individuals.

Given the results obtained in the present study, which are consistent with historical records and are in accordance with the genetic analysis performed previously in this osteological collection, we can now state that the Lagos's individuals were probably of African ancestry. Moreover, this study confirms the importance of investigating the ancestry in past populations. Future research on this collection will help address many questions of wider anthropological interest, namely regarding 
their overall health status, their labour conditions, and if they were subjected to physical abuse, among others.

\section{Acknowledgments}

The authors thank Centro de Investigação em Antropologia e Saúde, Centro de Ecologia Funcional, Dryas Arqueologia Lda., and Styx, Estudos de Antropologia Lda. The co-author Catarina Coelho was financed by University of Coimbra. The co-author David Navega was financed by national funds by FCT- Fundação para a Ciência e Tecnologia with the reference SFRH/BD/99676/2014. The co-author Maria Teresa Ferreira was financed by Gerda Henkel Foundation (AZ 09/F/15). The co-author Sofia N. Wasterlain was financed by national funds by FCT - Fundação para a Ciência e Tecnologia, under the project with the reference UID/ANT/00283/2013. The authors also acknowledge the anonymous reviewers whose valuable comments and suggestions allowed us to improve the manuscript.

The authors state that they do not have any conflict of interest to declare.

\section{References}

Bruzek J. 2002. A method for visual determination of sex, using the human hip bone. American Journal of Physical Anthropology 117: 157-168. DOI: 10.1002/ajpa.10012

Buikstra JE, Ubelaker DH. 1994. Standards for data collection from human skeletal remains. Arkansas Archaeological Survey Research Series No 44.

Byers SN. 2011. Introduction to forensic anthropology (4th Ed). Prentice Hall: Boston.

Caldeira AM. 2013. Escravos e traficantes no Império Português: o comércio negreiro português no Atlântico durante os séculos XV a XIX. A Esfera dos Livros: Lisboa. 
Coelho C. 2012. Uma Identidade perdida no mar e reencontrada nos ossos: avaliação das afinidades populacionais de uma amostra de escravos dos séculos XV-XVI. Masters Dissertation on Human Evolution and Biology. University of Coimbra: Coimbra.

DiGangi EA, Hefner JT. 2013.Ancestry estimation. In Research methods in human skeletal biology, DiGangi A, Moore MK (eds.). Academic Press: Oxford; 117-149.

Fielding A. 2007. Cluster and Classification Techniques for the Biosciences. Cambridge University Press: Cambridge.

Ferembach D, Schwidetzky I, Stloukal M. 1980. Recommendations for age and sex diagnoses of skeletons. Journal of Human Evolution 9: 517-49.

Ferreira MT, Neves MJ, Wasterlain SN. 2013. Lagos leprosarium (Portugal): evidences of disease. Journal of Archaeological Science 40: 2298-2307. DOI:10.1016/j.jas.2012.12.039

Fonseca J. 2010. Escravos e Senhores na Lisboa quinhentista. Edições Colibri: Lisboa.

Gill WG. 2009. Assessing Ancestry (Race) from the Skeleton. In The use of forensic anthropology, Pickering R, Bachman D (eds.). CRC Press: New York; 103-111.

Hastie T, Tibshirani R, Friedman, J. 2009. The Elements of Statistical Learning: Data Mining, Inference, and Prediction (2nd Ed). Springer: New York.

Hefner JT. 2009. Cranial Nonmetric Variation and Estimating Ancestry. Journal of Forensic Sciences 54: 985-995. DOI: 10.1111/j.1556-4029.2009.01118.x

Hefner JT, Ousley SD. 2014. Statistical Classification Methods for Estimating Ancestry Using Morphoscopic Traits, Journal of Forensic Sciences 59: 883-890. DOI: 10.1111/15564029.12421

Hughes CE, Juarez CA, Hughes TL, Galloway A, Fowler G, Chacon S. 2011. A Simulation for exploring the effects of the "trait list" method's subjectivity on consistency and accuracy of ancestry estimation. Journal of Forensic Sciences 56: 1094-1106. DOI: 10.1111/j.15564029.2011.01875.x 
Iscan MY, Steyn M. 2013. The Human Skeleton in Forensic Medicine (3rd Ed). Charles C. Thomas Publisher, Limited: Springfield.

Martiniano R, Coelho C, Ferreira MT, Neves MJ, Pinhasi R, Bradley DG. 2014. Genetic Evidence of African Slavery at the Beginning of the Trans-Atlantic Slave Trade. Scientific Reports 4: 5994. DOI: $10.1038 /$ srep05994

Osteoware. 2011. Standardized skeletal documentation software. Washinton, DC: Smithsonian Institution National Museum of Natural History. [computer program].

Ozle A, Van Niekerk P, Schulz R, Schmeling A. 2007. Studies of the chronological course of wisdom tooth eruption in a black African population. Journal of Forensic Sciences $\mathbf{5 2}$ : 1161-1163. DOI: 10.1111/j.1556-4029.2007.00534.x

Shirley NR, Jantz RL. 2011. Spheno-Occipital synchondrosis fusion in modern Americans. Journal of Forensic Sciences 56: 580-585. DOI: 10.1111/j.1556-4029.2011.01705.x

Uytterschaut HT. 1986. Sexual dimorphism in human skulls: a comparison of sexual dimorphism in different populations. Journal of Human Evolution 1: 243-50.

Viera AJ, Garrett JM. 2005. Understanding interobserver agreement: the kappa statistic. Family Medicine 37: 360-363.

Wasterlain SN, Neves MJ, Ferreira MT. 2015. Dental Modifications in a Skeletal Sample of Enslaved Africans Found at Lagos (Portugal). International Journal of Osteoarchaeology. DOI: $10.1002 /$ oa.2453 
Table 1. Sex diagnosis, age-at-death, preservation and completeness of the skeletal individuals analysed in the present study.

\begin{tabular}{|c|c|c|c|c|}
\hline Individual no. & Age-at-death & Sex & Preservation & Completeness \\
\hline 20 & $20-30$ years & Female & Fair & Almost complete \\
\hline 21 & 20-30 years & Female & Good & Almost complete \\
\hline 25 & $15-25$ years & Male & Good & Almost complete \\
\hline 38 & $20-30$ years & Female & Good & Almost complete \\
\hline 39 & 20-30 years & Female & Good & Almost complete \\
\hline 41 & $30-40$ years & Female & Good & Almost complete \\
\hline 57 & $15-25$ years & Female & Good & Almost complete \\
\hline 63 & $30-40$ years & Male & Poor & Very incomplete \\
\hline 65 & $25-35$ years & Male & Fair & Almost complete \\
\hline 66 & $30-40$ years & Male & Good & Almost complete \\
\hline 67 & $30-40$ years & Female & Good & Almost complete \\
\hline 68 & $30-40$ years & Female & Good & Almost complete \\
\hline 69 & $15-25$ years & Female & Fair & Relatively complete \\
\hline 75 & $30-40$ years & Female & Fair & Almost complete \\
\hline 77 & $30-40$ years & Male & Good & Almost complete \\
\hline 78 & $30-40$ years & Female & Good & Almost complete \\
\hline 81 & $15-25$ years & Female & Good & Almost complete \\
\hline 82 & $25-35$ years & Female & Good & Almost complete \\
\hline 93 & 20-30 years & Female & Good & Almost complete \\
\hline 95 & $20-30$ years & Female & Good & Almost complete \\
\hline 96 & $30-40$ years & Female & Good & Almost complete \\
\hline 110 & 20-30 years & Female & Fair & Almost complete \\
\hline
\end{tabular}




\begin{tabular}{cclll}
\hline 114 & $20-30$ years & Female & Good & Almost complete \\
\hline 123 & $20-30$ years & Female & Poor & Relatively complete \\
\hline 125 & $20-30$ years & Female & Good & Almost complete \\
\hline 133 & $15-25$ years & Female & Good & Almost complete \\
\hline 136 & $25-35$ years & Female & Fair & Relatively complete \\
\hline 150 & $30-40$ years & Female & Fair & Almost complete \\
\hline 153 & $25-35$ years & Female & Fair & Almost complete \\
\hline 162 & $20-30$ years & Female & Good & Almost complete \\
\hline 163 & $20-30$ years & Female & Fair & Almost complete \\
\hline 169 & $20-30$ years & Female & Fair & Almost complete \\
\hline 170 & $20-30$ years & Female & Fair & Relatively complete
\end{tabular}

Poor - Severe bone damage, metaphyseal loss with long bones and cancellous exposure of the vertebrae.

Fair - Slight bone damage, erosion of bone surface and/or bone fragmentation.

Good - No significant damage of the bone surface or bone fragmentation.

Very incomplete - More than $50 \%$ of the skeleton is absent.

Relatively complete $-25-50 \%$ of the skeleton is absent.

Almost complete - Less than $25 \%$ of the skeleton is absent. 
Table 2. Intra- and inter-observer error analysis using the Cohen's Kappa coefficient.

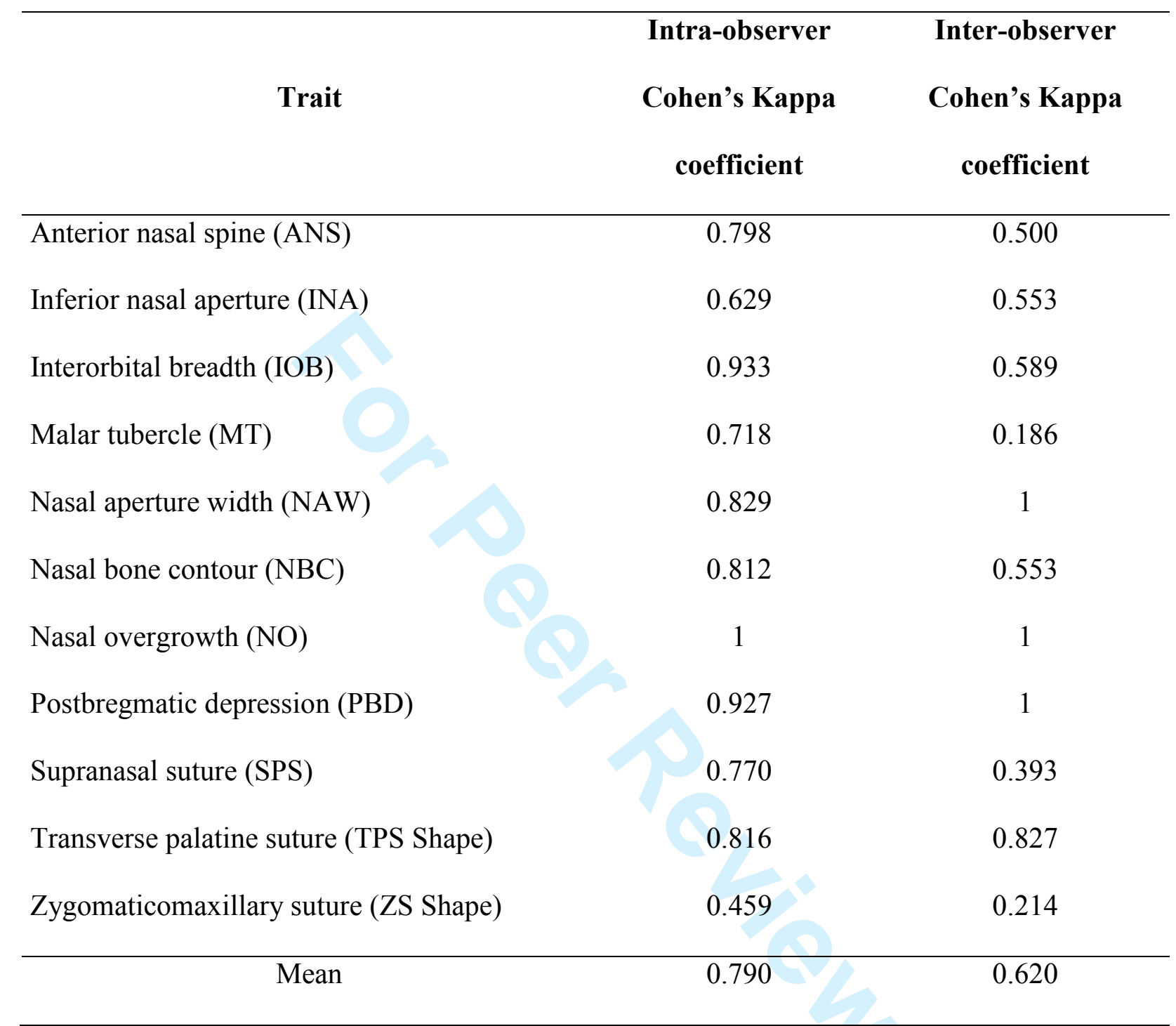


Table 3. Summary of the results obtained by comparing the individuals from Valle da Gafaria to four groups of ancestry classification.

\begin{tabular}{|c|c|c|c|c|}
\hline Individual no. & African & American Indian & Asian & European \\
\hline 20 & 0.550517 & 0.281084 & 0.155829 & 0.012571 \\
\hline 21 & 0.885845 & 0.064897 & 0.045798 & 0.003459 \\
\hline 25 & 0.993707 & 0.003025 & 0.002854 & 0.000414 \\
\hline 38 & 0.437627 & 0.296149 & 0.172366 & 0.093858 \\
\hline 39 & 0.754649 & 0.125582 & 0.073866 & 0.045902 \\
\hline 41 & 0.970815 & 0.003785 & 0.023625 & 0.001775 \\
\hline 57 & 0.994896 & 0.001698 & 0.003187 & 0.000219 \\
\hline 63 & 0.145385 & 0.635085 & 0.201174 & 0.018356 \\
\hline 65 & 0.998003 & 0.000274 & 0.001612 & 0.000110 \\
\hline 66 & 0.995642 & 0.002308 & 0.001885 & 0.000165 \\
\hline 67 & 0.993695 & 0.000229 & 0.005946 & 0.000130 \\
\hline 68 & 0.997024 & 0.001694 & 0.001156 & 0.000127 \\
\hline 69 & 0.998380 & 0.000000 & 0.001599 & 0.000000 \\
\hline 75 & 0.969394 & 0.004984 & 0.025250 & 0.000371 \\
\hline 77 & 0.982793 & 0.004169 & 0.011894 & 0.001144 \\
\hline 78 & 0.911316 & 0.005408 & 0.082632 & 0.000644 \\
\hline 81 & 0.995617 & 0.001484 & 0.001265 & 0.001635 \\
\hline 82 & 0.980205 & 0.004061 & 0.014015 & 0.001719 \\
\hline 93 & 0.956052 & 0.013309 & 0.025234 & 0.005406 \\
\hline 95 & 0.785586 & 0.083371 & 0.094501 & 0.036542 \\
\hline
\end{tabular}




\begin{tabular}{|c|c|c|c|c|}
\hline 96 & 0.976501 & 0.005867 & 0.016825 & 0.000808 \\
\hline 110 & 0.995931 & 0.001214 & 0.002762 & 0.000000 \\
\hline 114 & 0.998301 & 0.000181 & 0.001425 & 0.000000 \\
\hline 123 & 0.979222 & 0.005324 & 0.015074 & 0.000380 \\
\hline 125 & 0.579405 & 0.196752 & 0.213658 & 0.010185 \\
\hline 133 & 0.997265 & 0.000722 & 0.001931 & 0.000000 \\
\hline 136 & 0.999610 & 0.000000 & 0.000262 & 0.000000 \\
\hline 150 & 0.983811 & 0.010960 & 0.002163 & 0.003066 \\
\hline 153 & 0.981274 & 0.005890 & 0.009274 & 0.003562 \\
\hline 162 & 0.708830 & 0.224055 & 0.056727 & 0.010388 \\
\hline 163 & 0.886734 & 0.065532 & 0.042485 & 0.005249 \\
\hline 169 & 0.989513 & 0.004909 & 0.00526 & 0.000318 \\
\hline 170 & 0.995931 & 0.001214 & 0.002762 & 0.000000 \\
\hline
\end{tabular}


Table 4. Summary of the results obtained by comparing the individuals from Valle da Gafaria to two groups of ancestry classification.

\begin{tabular}{|c|c|c|}
\hline Individual no. & African & European \\
\hline 20 & 0.977675 & 0.022325 \\
\hline 21 & 0.996110 & 0.003890 \\
\hline 25 & 0.999583 & 0.000417 \\
\hline 38 & 0.823404 & 0.176596 \\
\hline 39 & 0.942662 & 0.057338 \\
\hline 41 & 0.998175 & 0.001825 \\
\hline 57 & 0.999780 & 0.000220 \\
\hline 63 & 0.887895 & 0.112105 \\
\hline 65 & 0.999889 & 0.000111 \\
\hline 66 & 0.999835 & 0.000165 \\
\hline 67 & 0.999869 & 0.000131 \\
\hline 68 & 0.999873 & 0.000127 \\
\hline 69 & 0.999993 & 0.000000 \\
\hline 75 & 0.999617 & 0.000383 \\
\hline 77 & 0.998838 & 0.001162 \\
\hline 78 & 0.999293 & 0.000707 \\
\hline 81 & 0.998361 & 0.001639 \\
\hline 82 & 0.998249 & 0.001751 \\
\hline 93 & 0.994378 & 0.005622 \\
\hline 95 & 0.955552 & 0.044448 \\
\hline
\end{tabular}

http://mc.manuscriptcentral.com/oa 


$\begin{array}{lll}96 & 0.999173 & 0.000827 \\ 110 & 0.999906 & 0.000000 \\ 114 & 0.999906 & 0.000000 \\ 123 & 0.999612 & 0.000388 \\ 125 & 0.982725 & 0.017275 \\ 133 & 0.999918 & 0.000000 \\ 136 & 0.999957 & 0.000000 \\ 150 & 0.996893 & 0.003107 \\ 153 & 0.996383 & 0.003617 \\ 162 & 0.985556 & 0.014444 \\ 163 & 0.994116 & 0.005884 \\ 169 & 0.999678 & 0.000322 \\ 170 & 0.999906 & 0.000000\end{array}$




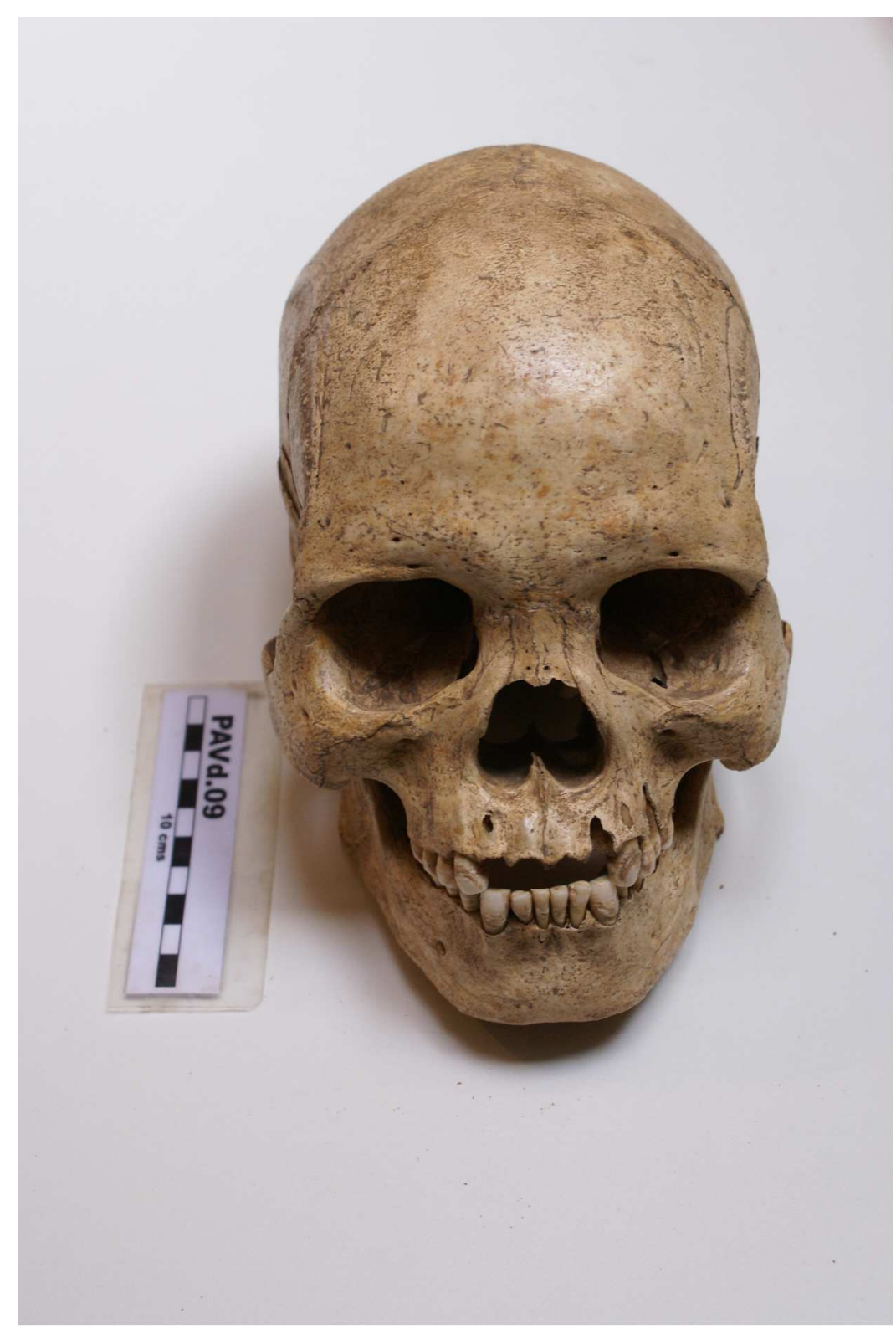

Figure 1. Cranium of individual 65 from Valle da Gafaria sample in anterior view, with an apparent African facial morphology. $914 \times 1365 \mathrm{~mm}(72 \times 72 \mathrm{DPI})$ 
Figure 2. Cranium of individual 63 from Valle da Gafaria sample in anterior view, which was assigned to the American Indian group when applying the four major ancestral groups (European, African, American Indian and Asian).

$1930 \times 1286 \mathrm{~mm}(72 \times 72 \mathrm{DPI})$ 